\title{
Study on the Corrosion Resistance and Wear Resistance of Micro-Arc Oxidation Coatings on the Clad Plate of Aluminum and Magnesium Alloy
}

\author{
Ruiling Jia ${ }^{1 a}$ Hongping Duan ${ }^{2 b}$ Feng Guo ${ }^{1}$ Xiwei Zhai ${ }^{1 \mathrm{c}}$ Yahong Liang $^{1}$ \\ ${ }^{1}$ Key Laboratory for superlight materials of Inner Mongolia, Inner Mongolia University of \\ Technology, Huhhot 010051,China \\ ${ }^{2}$ Institute of Mechanics, Chinese Academy of Sciences, Beijing, 100190, China \\ a jrl014014@163.com, b hpduan@imech.ac.cn, ${ }^{\mathrm{c}}$ xiweizhai@163.com
}

Key words: Aluminium; Magnesium Alloy; Explosive Cladding; MAO Coating; Corrosion Resistance; Wear Resistance

\begin{abstract}
Aluminium plate was cladded to magnesium alloy plate by using the explosive welding. The bonding morphology and composition of the explosive cladding plate was inspected by SEM and EDS. There is a wave bonding at the interface between aluminum plate and magnesium alloy plate. Then ceramic coatings were directly prepared on the surface of aluminum and magnesium alloy by micro-arc oxidation (MAO) in the same solution and at the same time. The microstructure and composition of MAO coatings were studies by SEM and EDS. The corrosion and wear resistance of MAO coatings on the two sides of the clad plate were investigated by salt spray tests and friction-wear test. The results show that the MAO coating on the Al surface consists of Al, O and Si elements, while MAO coating on the $\mathrm{Mg}$ surface consists of $\mathrm{Mg}, \mathrm{O}$ and $\mathrm{Si}$ elements. The corrosion resistance of MAO coating on the $\mathrm{Al}$ surface was better than that on $\mathrm{Mg}$ surface of the explosive clad plate. The MAO coatings both on the Al surface and on the $\mathrm{Mg}$ surface can obviously improve the wear resistance of substrate.
\end{abstract}

\section{Introduction}

Magnesium alloy is a lightweight and environmentally structural material. It is $20-25 \%$ lighter than aluminum alloy. However, the wear resistance and thermal stability of magnesium alloy is relatively poor, Magnesium alloy also cannot form a dense oxide film through spontaneous passivation like aluminum alloy [1]. If aluminum alloy is wrapped around magnesium alloy, it can improve the surface properties of magnesium alloy, such as wear resistance and corrosion resistance because the surface protection of aluminum alloy is more mature and perfected [2-4].

Explosive welding is a solid-state process in which controlled explosion forces to join two or more materials together under high pressures [5-7]. Using explosive cladding, the two lightweight, non-ferrous metals can be solidly combined, so that in use the advantages of both metals are displayed. Its application should be prevalent in aerospace, automotive, electronics and other industries.

MAO treatment was investigated recently on the surfaces of the same non-ferrous alloy, such as $\mathrm{Ti}, \mathrm{Al}$ and $\mathrm{Mg}$, etc, but any reports about the MAO treatment of the clad plate have not been seen. In this work, protective coatings were prepared on the surface of magnesium side and aluminum side of the explosive clad plate by MAO treatment in the same solution. It was investigated that the corrosion and wear resistance of the MAO coatings on the magnesium and aluminum clad plate.

\section{Experimental details}

The chemical composition of the aluminum plate and magnesium alloy plate are given in Table 1 . Aluminum was used as flyer plate and magnesium alloy was used as parent plate. Aluminum plate and magnesium alloy plate was designed with dimension of $100 \times 250 \times 3 \mathrm{~mm}$ and $100 \times 250 \times 5 \mathrm{~mm}$ respectively. The detonation velocity of the explosive material was $2800-3000 \mathrm{~ms}^{-1}$. 
All samples were polished to $0.5 \mu \mathrm{m}$ finish. The bonding interface examinations of welded samples were carried out using S-3400 scanning electronic microscope (SEM) with energy dispersive spectrometry (EDS).

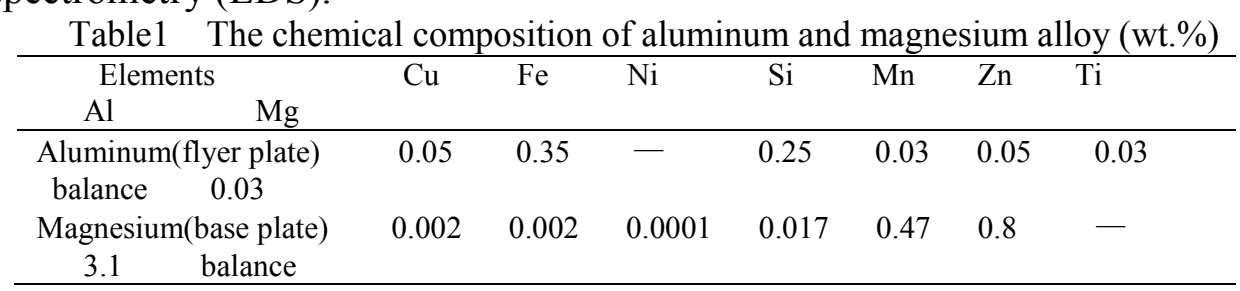

MAO coatings were prepared in $15 \mathrm{~g} / \mathrm{L} \mathrm{Na}_{2} \mathrm{SiO}_{4}$ and $1 \mathrm{~g} / \mathrm{L} \mathrm{KOH}$ solution under constant current density of $10 \mathrm{~A} / \mathrm{cm}^{2}$ for $0.5-1 \mathrm{~h}$. The salt spray test $(5 \% \mathrm{NaCl}$ solution) was used for corrosion resistant tests. After corrosion for $48 \mathrm{~h}$, the samples' morphologies were inspected using digital camera.

The friction and wear behavior was carried out by a cutting disk tribometer, a load of $5 \mathrm{~N}$ and rotation speed of 100r/min was chosen. After $30 \mathrm{~min}$, the weight loss of the samples was tested by an electronic balance with a resolution of $0.00001 \mathrm{~g}$.

\section{Results and discussion}

\section{The structure and composition of explosive clad plate}

The clad plate of aluminum and magnesium alloy has been achieved by explosive welding technique. As shown in Fig. 1, the interface has interlocked bonding between the aluminum plate and magnesium alloy plate, and the interface is outlined by the characteristic sharp transition (Fig. 1a). This type interface bonding endows the aluminium and magnesium alooy with enough cohesion strength. As shown in Fig. 1b, a $10 \mu \mathrm{m}$ band was observed between the interface of aluminum and magnesium, which maybe local melted zone. EDS analysis taken in this band (the lines in Fig. $1 \mathrm{~b}$ ) indicates that this band consists of $\mathrm{Al}$ and $\mathrm{Mg}$. The melted zone between the interface in the present work may be attributed to high kinetic energy in the jet which produced the heat and caused melting.
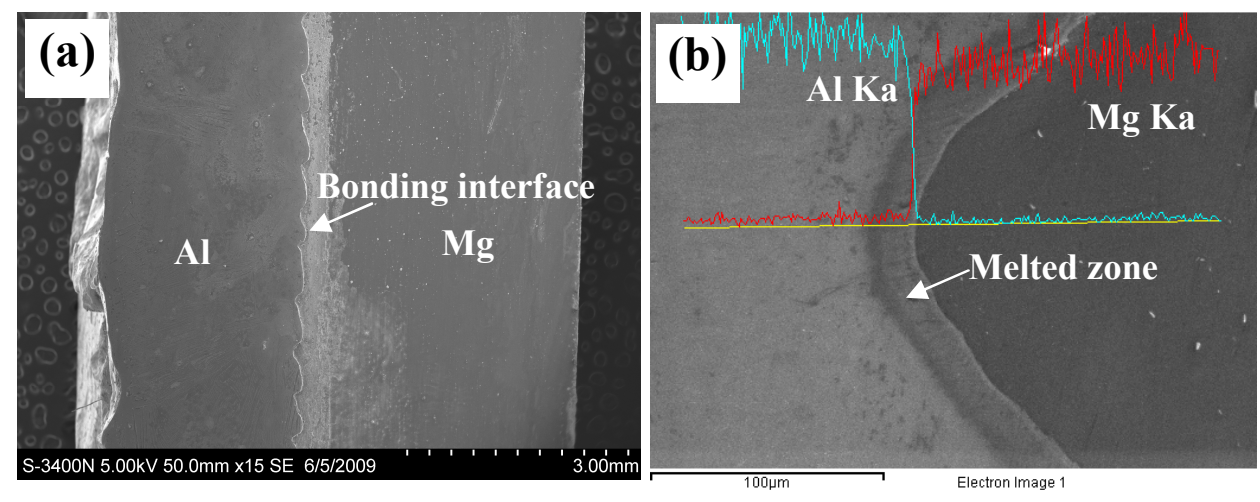

Fig.1 Morphologies of the interface of magnesium and aluminum along the bonding line

(a) Low magnitude morphology of interlocked interface of explosively clad plate

(b) Profiles of $\mathrm{Al}$ and $\mathrm{Mg}$ along the straight line

\section{MAO treatment for clad plate}

Fig. 2 shows the cross-section morphologies of the MAO coating on two side of the clad plate treated in the same electrolyte for the same time. As seen in Fig. 2a, the coating on the magnesium alloy surface exhibits a typical porous structure with some micro cracks. The coating on the aluminum surface is thicker and more compact than that on the magnesium alloy, which containing a porous inner layer and a dense outer layer (shown in Fig. 2b). The lower PB ratio is the main reason for the high porosity of MAO coating on the magnesium surface [10], which indicates that the coating on the aluminum surface of the clad plate should be more effective to improve the corrosion and wear resistance than that of the coating on magnesium alloy surface. 
Fig. 3 shows EDS pattern of the MAO coatings on the surfaces of magnesium alloy and aluminum. The result of Fig. 3(a) reveals that the coating of magnesium alloy mainly consists of $\mathrm{O}$, $\mathrm{Mg}, \mathrm{Si}$, with the atomic concentration of $54.11 \%, 15 \%$ and $7.3 \%$, respectively, which indicates the coating maybe compose of silicate of magnesium and magnesium oxide. From Fig. 3(b), it can be seen the composition of the coating on the aluminum surface is mainly $\mathrm{O}, \mathrm{Al}, \mathrm{Si}$ elements. The coating maybe compose of silicate of aluminum and aluminum oxide

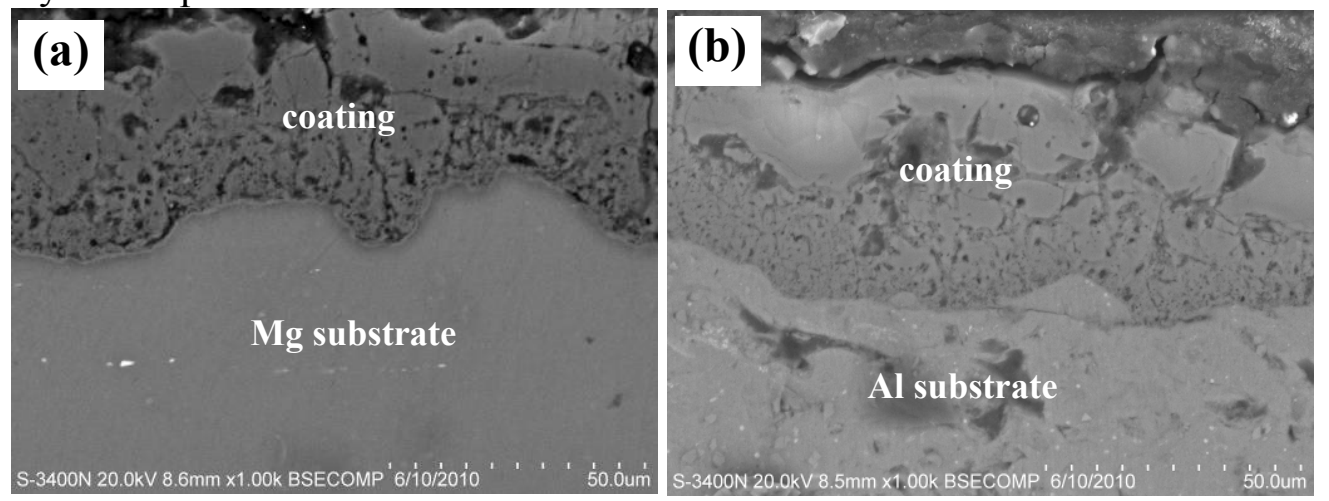

Fig. 2. Cross section morphology of MAO coating on (a) magnesium substrate and (b) aluminum substrate
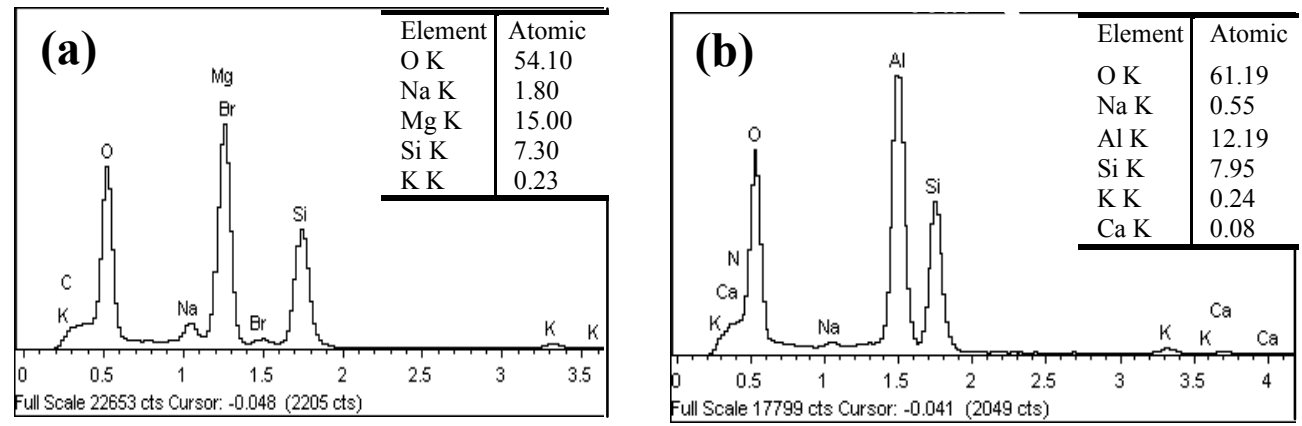

Fig.3 EDS spectra and composition of MAO coating (a) of magnesium alloy and (b) of aluminum.

\section{Corrosion behavior of the clad plate}

Fig. 4 shows the corrosion morphologies of uncoated and coated magnesium alloy and aluminum after exposure for $48 \mathrm{~h}$ in salt spray test. Uncoated $\mathrm{Mg}$ is seriously corroded as shown in Fig. 4(a), followed by uncoated Al serious corrosion (4(c)). The main corrosion form is localized corrosion for them. Comparing the four photos in Figure 4, it can be found the corrosion resistance of coated $\mathrm{Mg}$ or coated $\mathrm{Al}$ is obviously better than that of uncoated $\mathrm{Mg}$ or uncoated $\mathrm{Al}$, which indicates the two coatings both have protective effect. However, coated Al has better corrosion resistance than coated $\mathrm{Mg}$. The same conclusions can also be drawn from Figure 5. Coated Mg have the lower Tafel slope
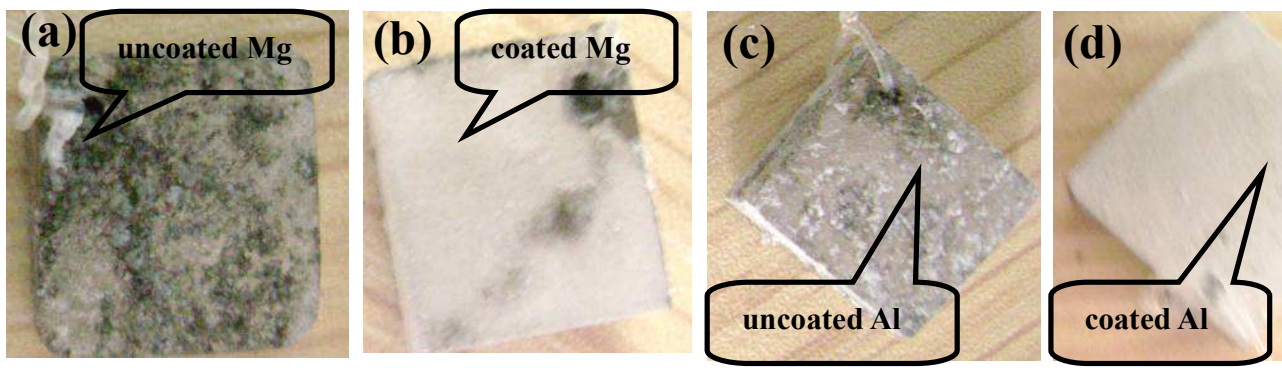

Fig. 4 Surface corrosion morphologies of the clad plate observed by digital camera

(a) and (b) uncoated and coated Mg. (c) and (d) uncoated and coated $\mathrm{Al}$

(line (a) in Fig. 5) because the active dissolution of the magnesium substrate was prevented by the MAO coatings in 5\% NaCl solution. The Tafel slope of coated Al (line (b) in Fig. 5) is slightly increased than that of the coated $\mathrm{Mg}$ side because the transfer of $\mathrm{Cl}-$ is held up for the higher corrosion resistance of the denser MAO coatings on aluminum. As mentioned previously, there are 
many irregular micro pores and cracks on the MAO coatings of the Mg side (as shown in Fig. 2(a)).So $\mathrm{Cl}$-would be rapidly transferred through the porous layer and reached the substrate, causing localized corrosion.

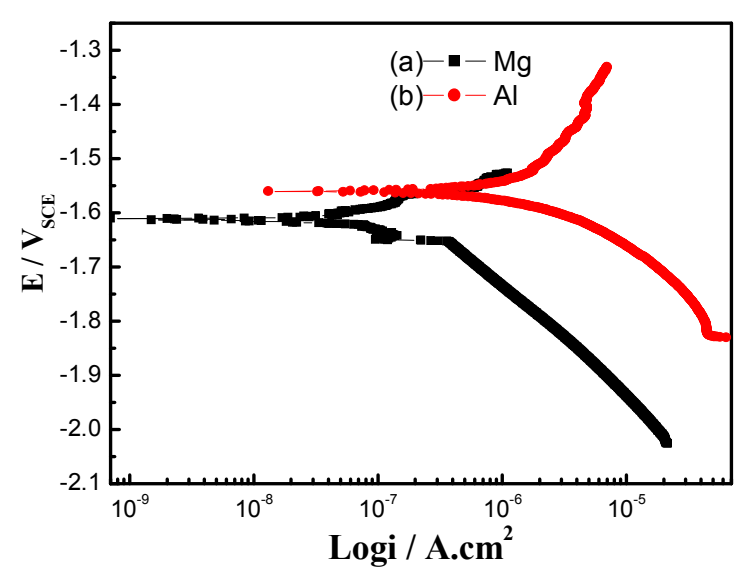

Fig. 5 Tafel polarization curves of MAO coatings on the $\mathrm{Mg}-\mathrm{Al}$ clad plate in $5 \% \mathrm{NaCl}$ solution

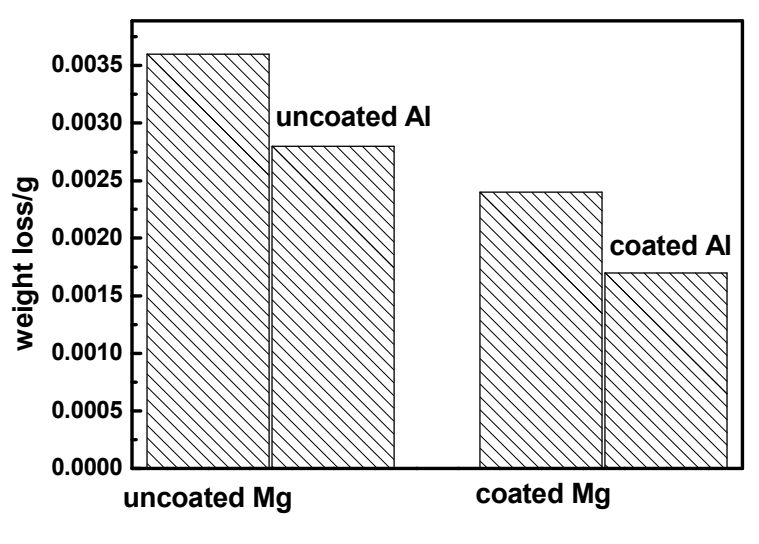

Fig. 6 Weight loss of the uncoated $\mathrm{Mg}$ or $\mathrm{Al}$ and coated $\mathrm{Mg}$ or $\mathrm{Al}$ of the clad plate

\section{Wear resistance of the clad plate}

The weight loss of uncoated and coated magnesium alloy and aluminum is shown in Fig. 6. The weight loss of uncoated $\mathrm{Mg}$ with $0.0036 \mathrm{~g}$ is the largest. For uncoated $\mathrm{Al}$, the weight loss is about $0.0024 \mathrm{~g}$. After MAO treatment, the wear resistance of the coated $\mathrm{Al}$ or coated $\mathrm{Mg}$ is both obviously enhanced. It was well known that the surface hardness of aluminium alloy could be increased evidently by the MAO treatment. The high hardness of the MAO coatings makes the weight loss of the coated magnesium or aluminium alloy decreased during friction test.

\section{Summary}

Aluminum plate can be cladded onto a magnesium alloy plate by the explosive welding technique. The interface had a wavy appearance and the melting zone can be seen in the interface between the cladded aluminum plate and magnesium alloy plate. MAO coatings can be produced on the surface of aluminum and magnesium alloy of the explosive clad plate in the same MAO treatment solution. MAO coatings on $\mathrm{Mg}$ surface are mainly composed of oxide and silicate of $\mathrm{Mg}$, while MAO coatings on aluminum surface are composed of oxide and silicate of Al. The coatings on the surface of aluminum and magnesium alloy of the claded plate both have protective effect. Coated Al has better corrosion resistance than coated $\mathrm{Mg}$, which is mainly due to their different composition and structure of the MAO coatings. The MAO coatings on the $\mathrm{Mg}-\mathrm{Al}$ clad plate can improve the wear resistance of aluminum plate and magnesium alloy plate.

\section{Acknowledgements}

This research work was supported by the scientific research item of Inner Mongolia University of Technology (ZD200913).

\section{References}

[1] G L Song, Recent Advanced Engineering Materials.7 (2005) 563.

[2] X Nie, E I Meletis, J C Jiang, A Leyland, A L Yerokhin, A Matthews. Surface \& Coatings Technology. Vol.149 (2002), p245. 
[3] G Sundararajan, L R Krishna. Surface \& Coatings Technology. Vol.167(2003), p269.

[4] L O Snizhko, A L Yerokhin, A Pilkngton, N L Gurevina, D O Misnyankin, A Leyland, A Matthews. Electrochimica Acta. Vol.49 (2004), p2085.

[5] C G SHI, Y H Wang, L Y Cai, L X Kang. Vol.23 (2002), p55 (In Chinese).

[6] S Gong, Z Li, Z Xiao, F Zheng. Materials and Design. Vol.30 (2009), p1404

[7] X Q Chen, K Y Zhang, F M Zhan. Vol.29 (2008), p105 (In Chinese)

[8] R Borrisutthekul, Y Miyashita, Y Mutoh. Science and Technology of Advanced Materials. Vol.6 (2005), p199

[9] X J Liu. Dalian University of Technology. Vol. 6 ((2007) (In Chinese)

[10] X. Zhou, G.E. Thompson, P. Skeldon, G.C. Wood, K. Shimizu, H.Habazaki. Corrosion Science.Vol.41 (1999), p1599. 


\section{Manufacturing Process Technology}

10.4028/www.scientific.net/AMR.189-193

Study on the Corrosion Resistance and Wear Resistance of Micro-Arc Oxidation Coatings on the Clad Plate of Aluminum and Magnesium Alloy

10.4028/www.scientific.net/AMR.189-193.1248

\section{DOI References}

[1] G L Song, Recent Advanced Engineering Materials.7 (2005) 563.

doi:10.1002/adem.200400164

[5] C G SHI, Y H Wang, L Y Cai, L X Kang. Vol.23 (2002), p55 (In Chinese).

doi:10.1142/S0252959902000407

[6] S Gong, Z Li, Z Xiao, F Zheng. Materials and Design. Vol.30 (2009), p1404

doi:10.1002/dmrr.939

[7] X Q Chen, K Y Zhang, F M Zhan. Vol.29 (2008), p105 (In Chinese)

doi:10.1016/S1872-2067(08)60032-7

[8] R Borrisutthekul, Y Miyashita, Y Mutoh. Science and Technology of Advanced Materials. Vol.6 2005), p199

doi:10.1016/j.stam.2005.05.004

[9] X J Liu. Dalian University of Technology. Vol. 6 ((2007) (In Chinese)

doi:10.1631/jzus.2007.A0079

[10] X. Zhou, G.E. Thompson, P. Skeldon, G.C. Wood, K. Shimizu, H.Habazaki. Corrosion cience.Vol.41 (1999), p1599.

doi:10.1002/(SICI)1096-9918(199910)27:10<950::AID-SIA658>3.0.CO;2-X

[4] L O Snizhko, A L Yerokhin, A Pilkngton, N L Gurevina, D O Misnyankin, A Leyland, A Matthews.

Electrochimica Acta. Vol.49 (2004), p2085.

doi:10.1016/j.electacta.2003.11.027

[8] R Borrisutthekul, Y Miyashita, Y Mutoh. Science and Technology of Advanced Materials. Vol.6 (2005), p199

doi:10.1016/j.stam.2005.05.004

[10] X. Zhou, G.E. Thompson, P. Skeldon, G.C. Wood, K. Shimizu, H.Habazaki. Corrosion Science.Vol.41 (1999), p1599.

doi:10.1002/(SICI)1096-9918(199901)27:1<57::AID-SIA464>3.0.CO;2-J 